\title{
ELABORAÇÃO DE CRITÉRIOS DE ANÁLISE PARA APLICATIVOS DE LÍNGUAS ESTRANGEIRAS COMO RECURSOS DIDÁTICOS AO ENSINO FORMAL ${ }^{1}$
}

\author{
GABRIELA MARÇAL NUNES (UFSC) $)^{2}$ \\ JULIANA CRISTINA FAGGION BERGMANN (UFSC) $)^{3}$
}

\begin{abstract}
RESUMO: Ainda que aplicativos com objetivos de aprendizagem de línguas estrangeiras sejam populares e conhecidos por proporcionar ao usuário um aprendizado individual e personalizado, eles também podem tornar-se recursos didáticos no ensino formal, com o intuito de auxiliar o professor e seu grupo a alcançarem seus objetivos. Entretanto, a grande demanda e existência de aplicativos com esse fim pode tornar a escolha do professor um grande desafio. Por essa razão, o presente artigo apresenta critérios de análise de aplicativos de LE com base no documento Marco Común Europeo de Referencia (2002) e outros autores, com a finalidade de auxiliar o professor na avaliação e escolha do aplicativo mais adequado. Como resultado, o professor poderá avaliar pontos dos aplicativos que vão além da aquisição linguística, como a sua interface gráfica, o desenvolvimento da habilidade comunicativa, questões de acessibilidade, interatividade e feedback.
\end{abstract}

PALAVRAS-CHAVE: Aplicativos de LE. Análise de Apps. Aprendizagens Móveis.

RESUMEN: Aunque las aplicaciones con objetivos de aprendizaje de lenguas extranjeras sean populares y conocidos por proporcionar al usuario un aprendizaje individual y personalizado, ellos también pueden volver-se recursos didácticos en la enseñanza formal, con el intuito de auxiliar el profesor y su grupo a lograren sus objetivos. Entre tanto, la gran demanda y existencia de aplicaciones con ese sin puede trasformar la elección del profesor en un gran reto. Por esa razón, el presente artículo presenta criterios de análisis de aplicaciones de LE basado en el documento Marco Común Europeo de Referencia para Lenguas Extranjeras (2002), y otros autores, con la finalidad de auxiliar el profesor en la evaluación y elección de la aplicación más adecuada. Como resultado, el profesor podrá evaluar puntos que están más allá de la adquisición lingüística, como: interface gráfica, desarrollo de la habilidad comunicativa, cuestiones de accesibilidad, interacción y feedback.

PALABRAS-CLAVE: Aplicaciones de LE. Análisis de Apps. Aprendizaje Móvil.

\section{INTRODUÇÃO}

O mundo passa por constantes revoluções tecnológicas. Cada Era é marcada por uma tecnologia que se sobressai e, hoje em dia, as tecnologias móveis digitais ganharam grande destaque na nossa sociedade atual, emergindo novas formas de comunicação (SANTOS; MADDALENA; ROSSINI, 2016) alterando de forma significativa a vida de crianças, jovens e adultos que estão expostos à ininterrupta e poderosa penetração social dessas novas

\footnotetext{
1 O presente trabalho foi realizado com apoio da Coordenação de Aperfeiçoamento de Pessoal de Nível Superior - Brasil (CAPES) - Código de Financiamento 001. This study was financed in part by the Coordenação de Aperfeiçoamento de Pessoal de Nível Superior - Brasil (CAPES) - Finance Code 001.

2 Mestranda (CAPES) no Programa de Pós-Graduação em Educação da Universidade Federal de Santa Catarina, na linha Educação e Comunicação. E-mail: mnunesgabriela@gmail.com

${ }^{3}$ Doutora em Sciences du Langage pela Université Lumière Lyon 2 - França, onde também cursou o Master (DEA). No Brasil, possui mestrado em Letras pela Universidade Federal do Paraná. É professora do Departamento de Metodologia de Ensino (MEN) da Universidade Federal de Santa Catarina (UFSC) e do Programa de Pós-Graduação em Educação (PPGE/UFSC), na linha Educação e Comunicação (ECO). E-mail: jcfbergmann@gmail.com
} 
tecnologias da informação e da comunicação (PÉREZ GÓMEZ, 2015). De acordo com Porto, Oliveira e Gama Neto (2016, p. 129) "é notória a forma como os avanços tecnológicos em formato de dispositivos multissensoriais, compostos por aplicativos, possuem uma parcela de responsabilidade pela alteração na forma com que o homem contemporâneo lida com as suas rotinas". Dessa forma, nota-se que o acesso à informação está cada vez mais simplificado e instantâneo. Os contatos entre culturas estão intensificados e todo o processo de globalização, pelo qual passamos, têm inúmeras consequências, sendo uma delas o fato de que cada vez mais pessoas, falantes de diferentes idiomas, estão estreitando contatos, formal e informalmente (GAVARRI, 2016). Sendo assim, deve-se pensar na língua estrangeira como um agente ampliador de informações, que aumenta as oportunidades de troca de conhecimento, sejam eles acadêmicos ou sociais.

Pensando no ensino de línguas estrangeiras, não se pode excluir a possibilidade do uso dos dispositivos móveis como ferramentas didáticas, já que é notável a forma como "os alunos incorporam, cada vez mais, a comunicação digital nas suas vidas e os seus dispositivos móveis passaram a fazer parte do seu ambiente pessoal de aprendizagem [...]" (MOURA, 2016, p. 163). Além disso, os dispositivos móveis têm a importante característica de acesso rápido e simplificado às mais diversas informações, possibilitando criar práticas inovadoras e motivadoras, que permitem a "contextualização da informação que melhor se adequa a situação em que o aprendiz se encontra (no tempo e no espaço) e ao que ele está realizando ou interessado naquele momento" (OLIVEIRA; MERCADO, 2016, p. 214). Esses aspectos, somados à possibilidade de acesso remoto, tornam os dispositivos móveis grandes facilitadores no processo de aprendizagem. Como asseveram Oliveira e Mercado (2016, p. 213) "[...]as tecnologias móveis podem ser utilizadas como um catalisador de uma mudança no paradigma educacional, que promovam a aprendizagem ao invés do ensino, que insiram o controle do processo de aprendizagem nas mãos do estudante". Sendo assim, aplicativos com objetivos de aprendizagem de línguas estrangeiras tornam-se uma opção de complementação às atividades formais, onde o aluno pode dedicar-se ao estudo e contato com a língua estrangeira em momentos extraclasse. Dessa forma, aquele que tem a possibilidade de inserir aplicativos de línguas estrangeiras no seu processo de aprendizagem tem a possibilidade de definir a hora em que prefere se dedicar à aprendizagem da língua adicional e, assim, organizar seus horários e tempo de dedicação ao estudo dessa nova língua (GAVARRI, 2016).

Aplicativos que têm por objetivo a aprendizagem de línguas estrangeiras vêm ganhando um notório espaço nas principais plataformas de distribuição de aplicativos (como Apple Store e Google Play), sobretudo na categoria 'educação', onde aparecem com grande destaque e sem que seja necessário ir até o campo de busca para encontrá-los. Segundo apontam as plataformas, tais aplicativos encontram-se em destaque nas abas de "mais populares" e "mais baixados" nos dispositivos móveis, dividindo espaço com diversos outros aplicativos das mais diversificadas áreas.

No entanto, por serem cursos online, suas atualizações e mudanças são constantes, assim como é frequente o surgimento de novos aplicativos, o que pode confundir aquele que se propõe a fazer uso de um dos aplicativos disponíveis. Além disso, aplicativos de línguas estrangeiras, assim como as tecnologias móveis em geral, podem ser utilizados como ferramentas de apoio às aulas presenciais de línguas estrangeiras, visando auxiliar o professor a compor suas atividades de desenvolvimento das habilidades comunicativas (de fala, escrita, audição e leitura), necessárias para a aprendizagem da nova língua. Segundo Sonego e Behar (2015, p. 523), 
os dispositivos móveis não foram planejados para uso educativo, mas podem ser facilmente incorporados nos planejamentos de aula, permitindo a realização de atividades de estudo dentro e/ou fora do momento escolar, com propósito educacional. A inserção dos dispositivos na prática docente tornase mais uma questão pedagógica do que tecnológica (SONEGO e BEHAR, 2015, p. 523)

Entretanto, a escolha do aplicativo adequado pode tornar-se um grande desafio. Após estabelecer os objetivos a serem alcançados por seus alunos, o professor pode seguir na busca do aplicativo que possa auxiliar seus alunos a alcançarem esse fim. Porém, o primeiro obstáculo aparece no momento da busca. As plataformas digitais estão repletas de aplicativos que têm como finalidade a aprendizagem de línguas estrangeiras, tornando a escolha uma tarefa desafiadora. Para ajudar na escolha, o professor poderia recorrer às análises já existentes e disponíveis nas mesmas plataformas, no entanto, essas análises são baseadas nas experiências pessoais de cada usuário, sem que tenham, necessariamente, fundamento teórico-científico, pois a função dessas plataformas é, apenas, distribuir aplicativos. Em razão disso, faz-se necessária uma análise simples, porém fundamentada, para que assim o professor possa destacar pontos realmente relevantes dos aplicativos selecionados e escolher o aplicativo mais adequado para seus alunos. Dessa forma, os critérios apresentados neste artigo têm como principal objetivo o de suprir tais necessidades, com questões diretamente direcionadas aos experts na área, os professores de línguas.

Diante disso, o presente artigo pretende destacar questões necessárias a serem analisadas nos aplicativos de línguas estrangeiras, resultando numa proposta de ferramenta de análise fundamentada, com o objetivo de auxiliar professores de línguas estrangeiras na escolha dos possíveis aplicativos que se adequem aos objetivos pré-estabelecidos pelo professor. Para Gardner e Davis (2014, p. 58) "[...] los alumnos buscan la aplicación relevante. La aplicación existe, están seguros de que el profesor sabe cuál es y que, para ser justo, debería proporcionársela a los alumnos de la manera más eficiente y directa posible".

\section{FUNDAMENTAÇÃO TEÓRICA}

É notável a grande mudança cognitiva no perfil atual do aluno (SANTAELLA, 2013), entretanto, essa mudança não se restringe apenas à parte cognitiva, mas também física, já que, como afirmam Souza e Couto (2016, p. 25), "os dispositivos tecnológicos são como próteses de seus corpos [...]". A atual juventude (porém, não limitada somente a ela) leva consigo um pequeno aparelho que, quando conectado à internet, possibilita ao usuário o acesso às mais diversas informações, conteúdos multimídia e interação com outros usuários. Santaella (2013) denomina esse novo perfil como ubíquo, referindo-se à ubiquidade do usuário, que pode estar presente em diversos lugares ao mesmo tempo:

Ao mesmo tempo em que está corporalmente presente, perambulando e circulando pelos ambientes físicos - casa, trabalho, ruas, parques, avenidas, estradas - lendo os sinais e signos que esses ambientes emitem sem interrupção, esse leitor movente, sem necessidade de mudar de marcha ou de lugar, é também um leitor imersivo. Ao leve toque do seu dedo no celular, em quaisquer circunstâncias, ele pode penetrar no ciberespaço informacional, assim como pode conversar silenciosamente com alguém ou com um grupo de pessoas a vinte centímetros ou a continentes de distância. O que lhe caracteriza é uma prontidão cognitiva ímpar para orientar-se entre nós e nexos multimídia, sem perder o controle da sua presença e do seu entorno no espaço físico em que está situado (SANTAELLA, 2013). 
Em outras palavras, o usuário que leva consigo esse pequeno aparelho pode desenvolver inúmeras tarefas, se fazer 'presente' em inúmeros lugares e espaços - virtualmente - em apenas alguns cliques. É através do celular que muitas pessoas, hoje, trabalham, estudam e realizam diversas tarefas cotidianas e, por conta disso, ele se torna um objeto importante para uma parte significativa da população. Ainda que tais aparelhos não tenham sido desenvolvidos para a área educacional, sua presença na vida cotidiana das pessoas pode dar novas perspectivas na parte educativa, já que hoje o acesso à informação está cada vez mais rápido e multimidiático; através do celular pode-se fazer buscas e acessar os mais diversos tipos de informação em apenas alguns cliques. Pensando nisso, levar esse novo contexto digital para dentro da escola, assim como formalizar o processo educativo em contextos não escolares, pode tornar o ato de aprender mais efetivo e, por muitas vezes, mais prazeroso. Dessa forma, as aulas se tornam mais dinâmicas e podem transcender o horário semanário, proporcionando que a aprendizagem aconteça em contextos diversificados, quando e onde o aluno pretenda (MOURA, 2016).

Pensando em como o uso de aparelhos móveis está inserido na sociedade e transformando o modo de viver, agir e interagir, a UNESCO (2013) elaborou diretrizes para seu uso na educação, mostrando que a interferência dos celulares na vida dos seus usuários não se limitaria apenas às interações sociais, mas se expandiria também para a forma de aprender, facilitando a aprendizagem individualizada, fornecendo um feedback das suas atividades e avaliação imediatas, permitindo a aprendizagem a qualquer hora e em qualquer lugar que lhe pareça adequado, apoiando a aprendizagem fora de sala de aula, dentre diversas outras possibilidades.

Quando se trata de aprendizagem de línguas estrangeiras, o uso de aplicativos é uma alternativa viável, pois possuem aspectos dos dispositivos móveis e permitem que a aprendizagem ocorra a qualquer hora e lugar desejados. Além disso, em muitos casos tratamse de cursos online, que possibilitam constante atualização, proporcionando um contato maior com a língua estrangeira. O uso de aparelhos móveis possibilita a interação entre estudantes, entre nativos, transformando a comunicação social também em uma forma de aprender. De acordo com Leffa (2006a), a internet permite ao usuário integrar-se a comunidades autênticas, e trocar experiências com nativos, mostrando que o uso desta tecnologia pode propiciar um ensino mais dinâmico de línguas estrangeiras.

\section{APLICATIVOS MÓVEIS}

Um aplicativo, também conhecido como 'app', pode ser definido como um programa de informática feito para dispositivos móveis que permite ao usuário realizar diversas operações,

una app puede ser limitada o amplia, sencilla o compleja... y tanto en un caso como en el otro, está perfectamente controlada por la persona u organización que la haya diseñado. Las aplicaciones dan acceso a música y a diarios como el New York Times, permiten jugar y hasta rezar, responden preguntas o formulan interrogantes nuevos. Lo más importante es que son rápidas, satisfacen una demanda y aparecen justo a tiempo. Podemos entenderlas como atajos que nos llevan directamente a donde queremos ir, sin necesidad de hacer búsquedas en línea o, si somos de la vieja escuela, en nuestra propia memoria (GARDNER; DAVIS, 2014, p. 20).

Como afirmam Gardner e Davis (2014) os aplicativos estendem-se a inúmeras atividades cotidianas, e são justamente conhecidos por promover essa facilidade em desenvolver tantas tarefas com a popularidade e acessibilidade que os aparelhos móveis 
proporcionaram. A notoriedade é facilmente compreendida através do número de aplicativos disponíveis nas plataformas de 'download', e também, através da expansão de categorias de acordo com cada âmbito da vida cotidiana, inclusive, na área educacional.

Nesta perspectiva, pode-se afirmar que o uso de aplicativos para aparelhos móveis ampliou o universo da educação a distância, dando oportunidade às pessoas escolherem recursos e métodos alternativos de se aprender uma língua estrangeira, já que permitem uma aprendizagem personalizada e, por muitas vezes, mais acessível.

Contudo, a popularidade fez com que aumentasse a oferta de aplicativos disponíveis, trazendo um dilema àqueles que se propõem a fazer uso de um desses apps: por um lado se tem muitas opções de escolha; por outro, cria-se uma dificuldade de se saber qual aplicativo é o mais adequado para atingir o objetivo pré-estabelecido.

Nestas plataformas, a categoria "Educação" é bastante extensa, se consideramos que possui mais de 300 aplicativos, número alto em comparação com outras categorias, dos mais diversos assuntos e propostas. A variedade de aplicativos contempla temas que vão desde revisões para grandes avaliações, como o ENEM, até atividades de lógica, matemática e, claro, a aprendizagem de línguas estrangeiras. Durante uma busca, sem pretensões de ser exaustiva, notou-se que a procura por aplicativos que têm a finalidade de aprender uma língua estrangeira está em grande destaque, sendo eles os mais frequentes na subcategoria 'Top 100', e entre os primeiros mais populares no Brasil. O ranking é organizado pela popularidade dos aplicativos, estando os mais 'baixados' nas primeiras colocações, o que evidencia o grande interesse pelos aplicativos de línguas estrangeiras.

Ainda que o uso de aparelhos móveis venha ganhando espaço na vida das pessoas, o seu uso vai na contramão do que atualmente acontece nas escolas, já que sua utilização é bastante restrita, e encontra diversos obstáculos. O ensino de línguas também vem passando por desafios, com a diminuição do ensino de línguas estrangeiras na escola e, em especial, quanto à sua diversidade de oferta. A mudança da Lei de Diretrizes e Bases da Educação, após a Lei $n^{\circ}$ 13.415, de 2017, refletida diretamente na Base Nacional Comum Curricular, determinando a obrigatoriedade do ensino da língua inglesa a partir do fundamental II, deixa a aprendizagem de outras línguas apenas para os casos em que seja possível a aprendizagem de mais de um idioma.

Pensando nisso, o uso de aplicativos poderia auxiliar de alguma maneira o grupo a alcançar os objetivos por ele pré-estabelecidos e, dessa forma, levar, também, a aprendizagem da língua estrangeira para o mundo fora de sala de aula, além de, quem sabe, incentivá-lo a estudar uma (ou muitas) outra(s) língua(s) estrangeira(s) diferente daquela aprendida na escola. Entretanto, a escolha do aplicativo pode ter impacto negativo no processo de aprendizagem caso não seja adequado aos objetivos pré-estabelecidos pelo professor e aluno. Nesse caso, a importância de estabelecer e ter definidos os objetivos da aprendizagem são tão importantes quanto estipular e determinar os critérios a serem analisados. Sendo assim, faz-se necessário, também, parâmetros que facilitem e otimizem a escolha do professor pelo aplicativo mais adequado.

\section{FERRAMENTA DE ANÁLISE DE APLICATIVOS DE LE}

O uso de aplicativos de línguas estrangeiras no ensino regular do Brasil ainda é bastante recente, assim como pesquisas que envolvam esse tipo de prática. Em breves buscas nas bases brasileiras de dados e periódicos, são poucas as investigações e relatos que apresentam a inserção dos aplicativos de línguas estrangeiras às práticas formais. Tais resultados podem ser reflexo de uma realidade dificultosa dos professores em poder dedicar-se a investigação e experimentação dessas novas ferramentas. 
Outro desafio se dá na seleção do aplicativo. São dezenas de aplicativos com a mesma finalidade - a aprendizagem de línguas estrangeiras -, ou seja, a escolha pelo mais adequado torna-se dificultosa sem que se tenha critérios pré-estabelecidos e fundamentados.

Para a elaboração de critérios de análise são necessários levar em conta diversos fatores do processo de aquisição de uma língua. Como forma de auxílio, e documento base, o Marco Común Europeo de Referencia para Lenguas Extranjeras (CONSEJO DE EUROPA), de 2002 em sua versão em língua espanhola, determinou pontos importantes para o desenvolvimento da competência comunicativa. Além do MCER (2002) com foco na aquisição da língua, outros pontos são necessários quando se trata de análise de aplicativos, como a interface gráfica e a interação entre homem máquina. Para tais pontos, outras ferramentas foram de grande importância, como a ficha desenvolvida pelas autoras Crescenzi \& Grané (2016).

Para avaliar um aplicativo de línguas estrangeiras, além de informações genéricas dos aplicativos, são necessários elaborar e destacar alguns pontos tal qual um material didático. Avaliando as habilidades a serem desenvolvidas quando se tem o objetivo de aprender uma língua estrangeira, destaca-se a abordagem comunicativa com suas 04 competências mais relevantes: compreensão, expressão, interação e mediação (CONSEJO DE EUROPA, 2002)

La competencia lingüística comunicativa que tiene el alumno o usuario de la lengua se pone en funcionamiento con la realización de distintas actividades de la lengua que comprenden la comprensión, la expresión, la interacción o la mediación (en concreto, interpretando o traduciendo). Cada uno de estos tipos de actividades se hace posible en relación con textos en forma oral o escrita, o en ambas (CONSEJO DE EUROPA, 2002, p. 14).

Partindo desse pressuposto, espera-se que um aplicativo - que tem por objetivo a aprendizagem de línguas estrangeiras - contemple as habilidades necessárias de acordo com os interesses e objetivos de cada usuário.

Assim como as questões de aprendizagem, outro ponto importante a analisar são os dados técnicos dos aplicativos, começando é claro pelo seu nome, o que facilitará a sua identificação em momentos de busca de dados. Também importante é distinguir o seu desenvolvedor, isso porque geralmente empresas de desenvolvimento de aplicativos possuem características próprias, que as distinguem de outras, ao mesmo tempo que aproximam seus próprios aplicativos, criando uma marca.

$\mathrm{O}$ ano de desenvolvimento e ano de atualização também se tornam fatores importantes no momento da escolha, pois facilitam na identificação do aplicativo que está atualizado ou que será descontinuado. Caso o professor deseje fazer uso do(s) aplicativos, verificar o preço é de grande relevância, já que alguns aplicativos são pagos, outros parcialmente pagos e outros gratuitos, tornando esse ponto de extrema importância para que o trabalho possa ser feito de acordo com o que o aplicativo permite.

Conhecer e identificar o sistema operacional a ser usado permite, além de assinalar a disponibilidade nos diferentes sistemas, também identificar se existe diferenças no aplicativo entre os sistemas IOS ou Android. Além disso, verificar a disponibilidade do uso off-line do aplicativo pode facilitar em momentos em que rede de internet não está funcionando, ou alunos que não possuem pacote de dados, como o intuito é levar o aplicativo para momentos extraclasse, a execução de atividade sem estar conectado passa a ser um critério importante.

A oferta de outros idiomas também é critério de análise, pois é interessante saber se o aplicativo permite ser utilizado em outras línguas estrangeiras - e quais delas - ou se restringe 
apenas a uma ou duas específicas; e por fim, tomar conhecimento da idade indicativa, é necessário para que o grupo tenha acesso aos conteúdos indicados para faixa etária.

A interface gráfica também é um ponto significativo a ser analisado no aplicativo, pois trata-se de como é composta a tela do aplicativo, como se dá a navegação, se é de forma simples, intuitiva, ou mais complexa. Nessa categoria são analisados pontos como: composição da tela, a forma como a tela inicial e até mesmo a tela que aparece no momento de desenvolver alguma atividade aparece pode interferir no desempenho e até mesmo na atenção do usuário. Muitas imagens, muitos textos, cores fortes podem dividir a atenção do usuário e prejudicar seu desempenho. Presença e interferências internas e externas, tais como: anúncios ou mensagens publicitárias, ícones, sons figuras que aparecem 'aleatoriamente' são pontos também que podem dividir a atenção e prejudicar o desempenho. Distribuição do conteúdo, a forma como ela é apresentada é importante para que assim o professor possa, com rapidez, identificar o que é relevante para seus alunos e o que pode ser trabalhado em outro momento.

Igualmente importante é saber se as atividades estão presentes seguindo um contexto, ou uma linha de conteúdo. O acesso a esses conteúdos também é um ponto fundamental a ser analisado pois o professor, nesse momento, saberá se o aplicativo permite que se navegue livremente pelos conteúdos pré-estabelecidos, ou se as unidades presentes no aplicativo dependem da execução de outras atividades, ou seja, unidades bloqueadas como prérequisitos.

Após a análise desses aspectos técnicos, pode-se iniciar a observação das habilidades comunicativas (escrita, leitura, audição e oralidade). Primeiramente, são levadas em conta as atividades de expressão, oral e escrita, separadamente. Nessas duas categorias são destacados a interação entre usuários que, segundo Leffa e Irala (2014, p. 206) "[...] independente do contexto de aprendizagem (natural ou formal), é preciso que haja contato com a língua e seu uso em situações de interação [...]", ou seja, é nesse momento que o usuário vai expressar-se, produzir texto falado ou escrito, a interação com outros usuários, ou nativos, pode despertar um interesse maior nessa construção do conhecimento. O aluno saberá que seus textos estarão chegando a outras pessoas e, sendo assim, o intercâmbio de informações será real. Leffa (2006b) também afirma que a interação produz uma mudança nos participantes, ainda que não sejam todos da mesma natureza, a interação pode existir das maneiras mais diversas, como entre pessoas e objetos.

A análise de atividades de expressão oral, inicialmente deve começar com a seguinte questão: se o aplicativo possui, ou não, atividades que contemplem essa habilidade. Assim como já citado, outro ponto importante aqui é a possibilidade, ou não, de interação com outros usuários. Outro aspecto relevante é o estímulo a fala espontânea. Segundo o Marco Común Europeo de Referencia para las lenguas (CONSEJO DE EUROPA, 2002), tarefas não robotizadas exigem do aluno o desenvolvimento e uso de estratégias comunicativas. Sendo assim, a presença de tarefas onde o aluno é desafiado a debater um tema, dar uma entrevista, pedir ou dar informações, são momentos onde ele poderá desenvolver suas estratégias de comunicação oral. Entretanto, o aplicativo pode não apresentar nenhum desses aspectos acima e, se não os apresenta, as atividades de expressão oral podem limitar-se à leitura em voz alta ou à repetição de orações, que também são pontos interessantes, podendo ser o objetivo do professor trabalhar aspectos fonéticos.

A análise de atividades de expressão escrita, também leva em consideração a interação; sendo assim, os textos escritos produzidos pelo aluno poderiam ter o intuito de serem entregues e lidos por outros usuários. Além desse ponto, outro aspecto relevante é a liberdade de escrita, se os textos produzidos são materiais já pré-estabelecidos, ou se permitem a escrita criativa. Nesse tópico, o professor pode fazer o uso do aplicativo como uma forma de despertar 
em seus alunos, quem sabe, o gosto pela escrita. Segundo Gardner e Davis (2014) o uso das tecnologias permite que muitos adolescentes sejam criativos, elevam o teto e ampliam as paredes para os jovens.

Seguindo com as categorias de atividades, vêm as duas de compreensão, tanto leitora quando auditiva, também separadas. De uma maneira geral, as duas categorias apresentam aspectos em comum, assim como as atividades de expressão. Neste caso, o que se destaca é a presença de materiais autênticos, ou seja, materiais produzidos para fins comunicativos e não para o ensino de língua. Com a internet e tantos recursos que ela dispõe, o aplicativo pode apresentar com mais facilidade a presença desses materiais.

A análise de atividade de compreensão auditiva contempla, além da presença ou não de materiais autênticos, pontos como a interatividade entre usuários. Além disso, também busca verificar o objetivo de cada tarefa, que pode basear-se apenas em captar a essência do que foi escutado, traduzir uma oração, ou transcrever uma oração etc.

A categoria de atividades de compreensão leitora busca analisar, também, a natureza de tais atividades, se baseiam apenas na interpretação de textos, se são atividades de leitura relacionada com imagens, ou tradução de orações; também são analisados os gêneros textuais apresentados no aplicativo, se possuem ou não a diversidade de gêneros e, caso apresentem, qual a natureza desses gêneros, se são de meios de comunicação, artigos, intercâmbio de mensagens, ou seja, se apresentam textos acadêmicos, textos de cunho jornalístico, obras literárias, etc.

Outros dois pontos importantes a serem observados são questões de interatividade e acessibilidade. Nesse caso, a interatividade contempla as redes sociais, a interação com amigos, porém não somente isso, a interação também pode dar-se de outras formas, como em formato de ajuda e de tutoria. Além disso, também se destacam a presença, ou não, de ajudas e como podem, ou não, aparecer para o usuário. Para o desenvolvimento de certas tarefas, ou atividades, é importante que o aluno tenha claro os objetivos a serem alcançados, nesse caso, a presença dos ícones de ajuda se fazem necessários. Essas ajudas podem ser como explicações gramaticais, regras, etc. Elas podem aparecer mediante requerimento do usuário através do clique, ou de forma 'espontânea'. A interatividade também pode aparecer com aspectos de gamificação, ou seja, pode haver rankings, caso o aplicativo seja gamificado. Caso seja, o aplicativo também pode apresentar limites de tempo para resposta ou graus de dificuldade, por exemplo, elementos característicos de um jogo.

Por fim, a acessibilidade trata da adaptação para deficientes visuais ou auditivos, cegos e surdos. Por ser um material digital, os aplicativos podem - ou deveriam poder - oferecer a possibilidade de adaptação das atividades e tarefas àqueles que necessitam. Esses aspectos são de extrema importância, não apenas como elementos de inclusão, mas para poder alcançar uma maior interação entre usuários, caso haja.

Para finalizar, o último aspecto a ser analisado é o feedback, pois é uma forma do aluno saber seu desempenho no desenvolvimento de certas tarefas. Sendo assim, o feedback se torna uma categoria muito importante no processo de aprendizagem, pois torna-se também uma forma de ajuda para alcançar êxito no seu objetivo. Pensando nisso, é importante que os feedbacks não apareçam apenas para reportar erros, mas também acertos. Para Paiva (2006) o feedback é o combustível da interação em qualquer contexto que ocorra, mesmo que essa interação seja entre homem e máquina.

\section{CONSIDERAÇÕES FINAIS}

Em síntese, pode-se afirmar que o uso das tecnologias móveis, sobretudo de aplicativos, está cada dia mais difundido, oportunizando a possibilidade de surgimento de novos 
aplicativos que desenvolvem atividades cada vez mais complexas. Com isso, nota-se que o âmbito educacional vem adaptando e se apropriando dessas novas tecnologias de maneira significativa. Dessa forma, o uso dessas tecnologias, especialmente de aplicativos, como ferramentas de apoio ao ensino formal da língua estrangeira, mostra-se como um caminho viável ao professor que deseja auxiliar seus alunos extraclasse.

Com isso, é importante que o professor conheça de uma forma mais profunda os aplicativos disponíveis e, assim, possa escolher aquele que melhor se adeque às necessidades do seu grupo. Entretanto, as análises disponíveis dos aplicativos são feedbacks de usuários, ou seja, partem de uma experiência pessoal e individualizada, não são análises fundamentadas.

Como resultado, deu-se a elaboração de uma ferramenta de análise de aplicativos, que tem por objetivo auxiliar o professor de línguas estrangeiras a conhecer de forma mais aprofundada atividades e habilidades presentes nos aplicativos, para que assim possa escolher o que melhor se adequa aos objetivos traçados nas aulas, auxiliando seus alunos a atingi-los.

\section{REFERÊNCIAS}

CONSEJO DE EUROPA (2002). Marco Común Europeo de Referencia para lenguas: aprendizaje, enseñanza, evaluación (MCER). Madrid: Anaya (Disponível em: http://cvc.cervantes.es/obref/marco).

CRESCENZI, Lucrezia; GRANÉ, Mariona. Ficha de Análisis del contenido y el diseño interactivo de Apps para Niños. Barcelona: Comunicar, 2016

GAVARRI, Sandra Lorena. El aprendizaje de lenguas extranjeras mediado por las TIC: Aprender Inglés con Duolingo. In: El Toldo de Astier, 7 (12). 2016. En Memoria Académica. P. 56-65

GÓMEZ, Ángel I. Pérez. Educação na Era Digital: A escola educativa. Porto Alegre: Penso, 2015. 192 p.

LEFFA, Vilson J. A aprendizagem de línguas mediada por computador. In: Vilson J. Leffa. (Org.). Pesquisa em linguística aplicada: temas e métodos. Pelotas: Educat, 2006a, p. 11-36.

LEFFA, Vilson J.; IRALA, Valesca B. O ensino de outra(s) língua(s) na contemporaneidade: questões conceituais e metodológicas. In: LEFFA, Vilson J.; IRALA, Valesca B. Uma Espiadinha na Sala de Aula: Ensinando Línguas Adicionais no Brasil. Pelotas: Educat, 2014. p. 21-48.

LEFFA, Vilson J. Interação simulada: um estudo da transposição da sala de aula para o ambiente virtual. In: LEFFA, Vilson J. A interação na Aprendizagem das Línguas. 2. Ed. Pelotas: Educat, 2006b. Cap. 8. P. 175218.

MOURA, Adelina. Aplicativos para aprendizagem baseada em projetos. In: COUTO, Edvaldo; PORTO, Cristiane; SANTOS, Edméa. App-Learning: Experiências de pesquisa e formação. Salvador: Edufba, 2016. Cap. 9. p. 163-178.

OLIVEIRA, Carloney Alves de; MERCADO, Luís Paulo Leopoldo. Ensino de matemática utilizando o aplicativo QR Code no contexto das tecnologias móveis. In: COUTO, Edvaldo; PORTO, Cristiane; SANTOS, Edméa.

App-Learning: Experiências de pesquisa e formação. Salvador: Edufba, 2016. Cap. 12. p. 211-226.

PAIVA, Vera Lúcia Menezes de Oliveira e. Feedback em ambiente virtual. In: LEFFA, Vilson J. A interação na Aprendizagem das Línguas. 2. Ed. Pelotas: Educat, 2006. Cap. 9. P. 219-254.

PORTO, Cristiane de Magalhães; OLIVEIRA, Kaio Eduardo de Jesus; GAMA NETO, Edilberto Marcelino da. Realidade aumentada e a potencialidade educacional do aplicativo MAR. In: COUTO, Edvaldo; PORTO, Cristiane; SANTOS, Edméa. App-Learning: Experiências de pesquisa e formação. Salvador: Edufba, 2016. Cap. 7. p. 127-144.

SANTAELLA, L. Desafios da ubiqüidade para a educação. Novas Mídias e o Ensino Superior, São Paulo, p 1929, abr. 2013

SANTOS, Edméa; MADDALENA, Tania Lucía; ROSSINI, Tatiana Stofella Sodré. Diário Hipertextual Online de Pesquisa: uma experiência com o aplicativo Evernote. In: COUTO, Edvaldo; PORTO, Cristiane; SANTOS, Edméa. App-Learning: Experiências de pesquisa e formação. Salvador: Edufba, 2016. p. 93-108. SONEGO, Anna Helena Silveira; BEHAR, Patrícia Alejandra. M-learning: reflexões e perspectivas com o uso de aplicativos educacionais. In: Nuevas ideias em Informatica Educativa: memorias XVII Congreso Internacional de Informática Educativa, TISE. Santiago: Universidade do Chile, 2015. p. 521-526. v. 8. SOUZA, Joana Dourado França de; COUTO, Edvaldo Souza. Snapchat: viver e aprender em meio a mensagens autodestrutivas. In: COUTO, Edvaldo; PORTO, Cristiane; SANTOS, Edméa. App-Learning: Experiências de pesquisa e formação. Salvador: Edufba, 2016. Cap. 1. p. 23-37.

UNESCO, Organização das Nações Unidas para Educação, a Ciência, e a Cultura. Diretrizes de Políticas da UNESCO para a aprendizagem móvel. França, 2013. 